\title{
The Effectiveness of Traditional Media (Leaflet and Poster) to Promote Health in a Community Setting in the Digital Era: A Systematic Review
}

\section{Ardila Lailatul Barik, Rizki Agustin Purwaningtyas and Dwi Astuti}

Faculty of Nursing, Universitas Airlangga, Surabaya, Indonesia

\section{ABSTRACT}

Introduction: The use of health promotion media in the digital era, such as e-health and m-health, is increasing. However, traditional health promotion media, such as posters and leaflets, are still used. This review aimed to identify the effectiveness of the use of traditional health promotion media (leaflets and posters) in a community setting in the digital era.

Methods: The data was gathered using the following steps: (1) determining the topic, (2) determining the keyword chain, (3) looking for the relevant literature in the database and (4) analyzing the article. The search using a predetermined keyword chain in Scopus, Science Direct and Sage Journals produced 208 publications.

Results: After applying the inclusion and exclusion criteria, 16 publications were selected for review.

Conclusion: Traditional health promotion media such as leaflets and posters are still useful in the current digital era, especially for adult respondents. This form of media will be more effective when combined with other media such as videos, telephone interactions, games and others.
\end{abstract}

\section{ARTICLE HISTORY}

Received: Dec 26, 2019

Accepted: Dec 31, 2019

\section{KEYWORDS}

health promotion; traditional media; digital era

\section{CONTACT}

\section{Ardila Lailatul Barik}

$\triangle$ ardila.lailatul.barik2018@fkp.unair.ac.id

$\equiv$ Faculty of Nursing, Universitas Airlangga, Surabaya, Indonesia

Cite this as: Barik, A. L., Purwaningtyas, R. A., \& Astuti, D. (2019). The Effectiveness of Traditional Media (Leaflet and Poster) to Promote Health in a Community Setting in the Digital Era: A Systematic Review.Jurnal Ners, 14(3si), 76-80. doi:http://dx.doi.org/10.20473/in.v14i3(si).16988

\section{INTRODUCTION}

In the face of rapid digitalization, e-health and $\mathrm{m}$ health are increasingly being used. E-health is a health service conducted through the Internet and related technology, while $\mathrm{m}$-health is a health service utilized through a mobile application (Dang, Golden, Cheung, \& Roos, 2010 ; Power, 2018). However, traditional health promotion media, such as posters and leaflets, are still frequently used (Nitschke, Krackowizer, Hansen, Bi, \& Tucker, 2017; Zhu et al., 2017). Is the use of traditional media still effective in the current era of digitalization? As far as our knowledge goes, a review of the use of traditional health promotion media in the digitalization era has never been discussed previously.

Health promotion includes activities that aim to protect or improve health through improving the physical and social environment (John \& Published, 2015). Therefore, the role of health promotion is important. Previous research has shown that promotional tools influence the effectiveness of the promotions carried out (Al Bardaweel \& Dashash,
2018; Suswani, Arsunan, Amiruddin, Zulkifli, \& Ariyanti, 2018). Thus, choosing the right health promotion media is an important step that influences the success of the promotion.

This study aimed to determine the use of traditional health promotion media (leaflets and posters) in the digital era in the community. Who is effective at using the media, whether they be children, adults, or the elderly? What types of cases are in accordance with the promotional media, whether primary, secondary, or tertiary prevention? Where is the media often used; developed countries, developing countries or lagging countries? How is the media used, is it used alone or is it used with other promotional media?

\section{MATERIALS AND METHODS}

This study used a systematic review to analyze the use of traditional health promotion media in the era of digitalization in society. The study began with a 


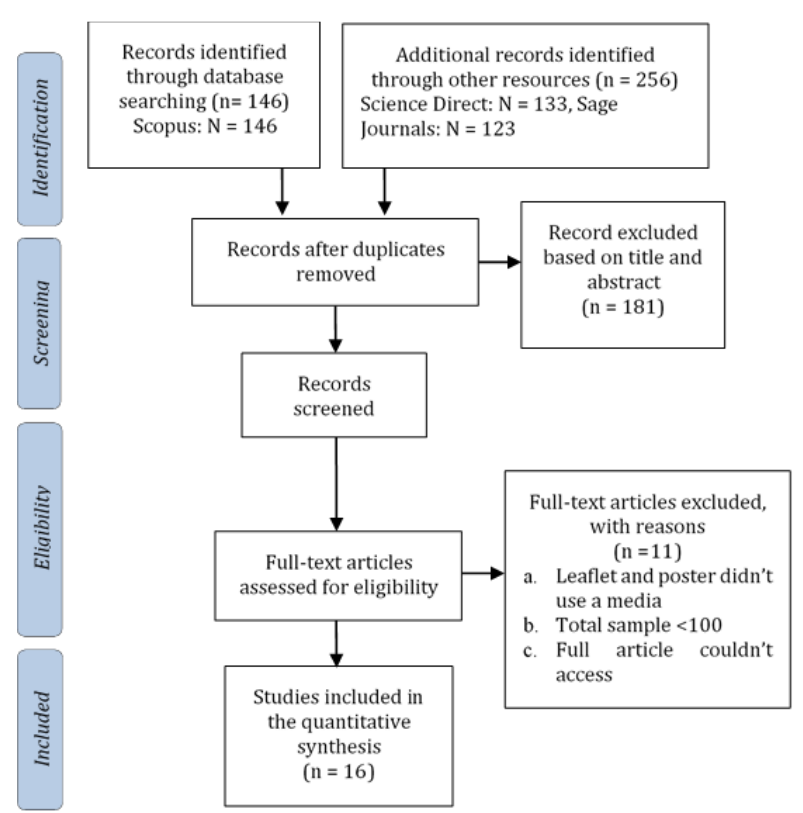

Figure 1. PRISMA study flow diagram

systematic literature search. To determine the chain of the keywords, two components were used as the search terms to identify studies on the use of traditional health promotion media (leaflets and posters) in the era of digitalization in the community: 1) health promotion or health education or health prevention and 2) leaflets or posters. The results of this keyword formulation were then used to find the relevant literature in the Scopus, Science Direct and Sage Journals databases. The keyword chain was as follows: "health promotion" OR "health education" OR "health prevention") AND ("leaflet" or "poster".

The search was limited to articles published between 2016 and 2018. The search results using the keyword chain and limitation criteria obtained 208 articles. The applied criteria for inclusion were publications in English, community-based research, not set in clinics, involving more than 100 samples, and using leaflets and or posters as promotional tools. Articles which only involved a trial and that had no results were excluded.

The first screening was based on a predetermined topic. After obtaining 402 articles that matched the keywords, the reviewers filtered the editorial titles to find out if there were duplicate journals. After deleting the duplicated journals, the reviewer sorted the articles according to the predetermined inclusion and exclusion criteria. The full article was then reviewed in the second screening. At this stage, the publication was considered to be potentially relevant if the title, abstract, and full content had a link to the review topic. Articles that meet the inclusion criteria were selected. The selected articles totaled 16 .

\section{RESULTS}

The chain of keywords shown above yielded 208 publications, which were included in the initial screening. The results of the screening have been presented in Figure 1. In the first screening, 181 publications were excluded after reading the title and abstracts based on the inclusion/exclusion criteria. In total, 27 publications were included for the second screening. For the second screening, the publications were downloaded. Finally, we obtained 16 publications, where 11 publications were excluded after reading the full text. The reasons for the exclusion were (1) leaflets and/or posters not use as intervention media, (2) the sample size not being fulfilled and (3) a combination of the above reasons. Thus, after the second screening, 16 publications were selected for the systematic review. A detailed description of the articles has been presented in the Appendix.

The characteristics of the included publications have been presented in Table 1. Publications were included if they were within the limitation of 3 years. Most of the studies took place in a developed country $(62,5 \%)$ such as Australia, the UK, the USA, the Netherlands, New Zealand and Canada. The remaining 37,5\% came from a developing country such as Hongkong, India, South Africa, Bangladesh, and Malaysia. Adults made up the most significant percentage of participants, by about $43,9 \%$. The second were the elderly, children and not mentioning a specific age at $18,7 \%$ respectively. Over half of the studies combined leaflets, posters and other media $(56,3 \%)$ such as billboards, flyers, newspapers, booklets, banners, brochures, handouts, slides, games, videos, e-mails, phones and movies; $25 \%$ used only leaflets and $18,7 \%$ used only posters as the intervention media. Almost all of the leaflets and/or posters in this study were used as the primary health prevention $(87,5 \%) ; 75 \%$ used leaflet, $66,7 \%$ used posters and $100 \%$ involved a combination of both with other media and they were reported as effective at increasing health status and knowledge.

This systematic literature review aimed to analyze the use of traditional health promotion media (leaflets and posters) in the era of digitization in society. From the results of the review, it was determined that the use of traditional media (leaflets and posters) is effective as a media channel for health promotion, especially among adults. Only a few publications reported studies that focused on groups of parents and children. The submission of messages referred to as props is divided into 11 (eleven) levels which at the same time describes the level of intensity of each of the aids in a cone. Occupying a cone base is the original object which has the highest intensity followed by human-made objects, plays, demonstrations, field trips, exhibitions, television, film, recordings/radio, writing and words.

The submission of material with writing (leaflets and posters) occupies the second cone peak, which can be interpreted as health promotion media with teaching aids in the form of writing being effective at delivering health promotions. The contribution of this form of media is that it channels knowledge into the brain via the eye. Approximately $75-87 \%$ of human knowledge is obtained/channeled through the eyes 
Table 1. The description of the relevant publications according to the analysis criteria

\begin{tabular}{|c|c|c|c|}
\hline Classification & Sub Category & Total (\%) & Reference index* \\
\hline \multirow[t]{3}{*}{ Publication year } & 2018 & $4(25)$ & $12,13,14,15$ \\
\hline & 2017 & $6(37,5)$ & $1,2,3,4,5,16$ \\
\hline & 2016 & $6(37,5)$ & $6,7,8,9,10,11$ \\
\hline \multirow[t]{4}{*}{ Respondents } & Elderly & $3(18,7)$ & $1,6,13$ \\
\hline & Adult & $7(43,9)$ & $4,7,8,9,11,12,14$ \\
\hline & Children & $3(18,7)$ & $2,5,15$ \\
\hline & Not mention a specific age & $3(18,7)$ & $3,10,16$ \\
\hline \multirow[t]{2}{*}{ Countries } & Developed countries & $10(62,5)$ & $1,2,3,5,6,9,11,12,13,15$ \\
\hline & Developing countries & $6(37,5)$ & $4,7,8,10,14,16$ \\
\hline \multirow[t]{3}{*}{ Media } & Leaflet & $4(25)$ & $1,4,10,11$ \\
\hline & Poster & $3(18,7)$ & $3,5,12$ \\
\hline & $\begin{array}{l}\text { Combination both leaflet, } \\
\text { poster, and other media }\end{array}$ & $9(56,3)$ & $2,6,7,8,9,13,14,15,16$ \\
\hline \multicolumn{4}{|c|}{ P } \\
\hline \multirow[t]{2}{*}{ Leaflet } & Effective & $3(75)$ & $1,10,11$ \\
\hline & Not effective & $1(25)$ & 4 \\
\hline \multirow[t]{2}{*}{ Poster } & Effective & $2(66,7)$ & 3,12 \\
\hline & Not effective & $1(33,3)$ & 5 \\
\hline \multirow{2}{*}{$\begin{array}{l}\text { Combination both leaflet, } \\
\text { poster, and other media }\end{array}$} & Effective & $9(100)$ & $2,6,7,8,9,13,14,15,16$ \\
\hline & Not effective & $0(0)$ & - \\
\hline \multirow[t]{3}{*}{ Health prevention } & Primary & $14(87,5)$ & $\begin{array}{l}1,2,3,5,7,8,9,10,11,12,13,14,15,16 \\
4,6\end{array}$ \\
\hline & Secondary & $2(12,5)$ & - \\
\hline & Tertiary & $0(0)$ & \\
\hline
\end{tabular}

*appendix is available on supplementary file

while the other $13-25 \%$ is channeled through the other senses (Susilowati, 2016).

Interventions for the use of traditional health promotion media (leaflets and posters) are more often applied as a form of primary or secondary prevention. Primary prevention is used to improve and maintain conditions that produce negative impacts on health (Susilowati, 2016). Even this is in accordance with the results of the review, which explains that media leaflets and posters are used to look for primers.

An analysis of the countries that are still using traditional health promotion media (leaflets and posters) was also carried out in this review. The results of the study indicate that many developed countries still use traditional media as the chosen health education media format in their community. This is because developed countries have a high reading habit. For example, Finland have won the title of a country with high reading interest from "The World's Most Literate Nations (WMLN) From Central Connecticut State University" (McCuskee et al., 2018).

\section{DISCUSSION}

Information dissemination program methods make use of a variety of media to offer information to the public about the risk of a particular lifestyle, choices and personal behavior as well as to advertise the benefits of changing that behavior and improving their quality of life. Promotional media is closely related to attractiveness, where it is intended to be able to attract attention, interest, and influence people. When linked to health, health promotions must be able to make the patients or individuals or communities of interest read it, pay attention to it and add their own insights. This is expected to be able to encourage prevention as an intervention to improve health status. Media promotion using leaflets and posters means that they cover a large population. They serve as a great medium to spread the health message. Messages on billboards/posters allow the sender to reach the target audience while they are on the move (Hoare \& Decker, 2016). The analysis of the articles showed that they will be more effective when combined with other media. The other media in question could be education from the health workers, videos, demonstrations, Focus Group Discussions (FGD) and games (Sheikh, Vadera, Ravey, Lovatt, \& Kelly, 2017).

The shortcomings of several articles reviewed have been included. For example, many had no control samples which could cause a bias in the results of the study. Many articles did not mention the age of the sample.

Various aspects that need to be considered for the selection of traditional promotional media (leaflets, posters) in the digitalization era should be taken into consideration when choosing health promotion media. Nurses should use leaflets as the preferred health promotion media, especially for adult patients. Leaflet media can play an important role in increasing knowledge, skills, and in changing the positive behavior in society. 


\section{CONCLUSION}

Traditional media used for health promotion, such as leaflets and posters, are still effective in the digital era, especially for adult respondents.

\section{REFERENCES}

Al Bardaweel, S., \& Dashash, M. (2018). E-learning or educational leaflet: Does it make a difference in oral health promotion? A clustered randomized trial. BMC Oral Health, 18(1), 1-8. https://doi.org/10.1186/s12903-018-0540-4

Beaujean, D. J. M. A., Crutzen, R., Gassner, F., Ameling, C., Wong, A., Van Steenbergen, J. E., \& Ruwaard, D. (2016). Comparing the effect of a leaflet and a movie in preventing tick bites and Lyme disease in the Netherlands. BMC Public Health, 16(1). https://doi.org/10.1186/s12889-016-3146-2

Borah, P. K., Kalita, H. C., Paine, S. K., Khaund, P., Bhattacharjee, C., Hazarika, D., ... Mahanta, J. (2018). An information, education and communication module to reduce dietary salt intake and blood pressure among tea garden workers of Assam. Indian Heart Journal, 70(2), 252-258.

https://doi.org/10.1016/j.ihj.2017.08.008

Chan, S. S. C., Cheung, Y. T. D., Fong, D. Y. T., Emmons, K., Leung, A. Y. M., Leung, D. Y. P., \& Lam, T. H. (2017). Family-Based Smoking Cessation Intervention for Smoking Fathers and Nonsmoking Mothers with a Child: A Randomized Controlled Trial. Journal of Pediatrics, 182, 260266.e4.

https://doi.org/10.1016/j.jpeds.2016.11.021

Cockayne, S., Adamson, J., Clarke, A., Corbacho, B., Fairhurst, C., Green, L., ... Torgerson, D. J. (2017). Cohort randomised controlled trial of a multifaceted podiatry intervention for the prevention of falls in older people (The REFORM Trial). PLoS ONE, 12(1), 1-15. https://doi.org/10.1371/journal.pone.0168712

Cox, S. N., Guidera, K. E., Simon, M. J., Nonyane, B. A. S., Brieger, W., Bornman, M. S., \& Kruger, P. S. (2018). Interactive Malaria Education Intervention and Its Effect on Community Participant Knowledge: The Malaria Awareness Program in Vhembe District, Limpopo, South Africa. International Quarterly of Community Health Education, 38(2), 147-158. https://doi.org/10.1177/0272684X17749573

Dang, S., Golden, A. G., Cheung, H. S., \& Roos, B. A. (2010). Telemedicine Applications in Geriatrics. In Brocklehurst's Textbook of Geriatric Medicine and Gerontology (SEVENTH EDITION). https://doi.org/10.1016/B978-1-4160-62318.10128-X

Hoare, K. J., \& Decker, E. (2016). The role of a sexual health promotion leaflet for 15-18 year olds in catalysing conversations: A constructivist grounded theory. Collegian, 23(1), 3-11. https://doi.org/10.1016/j.colegn.2015.01.002

John, B., \& Published, K. (2015). Health Promotion: Ideology, discipline and specialism. Australian and
New Zealand Journal of Public Health, 39(6), 593593. https://doi.org/10.1111/1753-6405.12417

Katz, M. L., Young, G. S., Reiter, P. L., Pennell, M. L., Plascak, J. J., Zimmermann, B. J., ... Paskett, E. D. (2017). Process Evaluation of Cancer Prevention Media Campaigns in Appalachian Ohio. Health Promotion Practice, 18(2), 201-210. https://doi.org/10.1177/1524839916641638

Keihner, A., Rosen, N., Wakimoto, P., Goldstein, L., Sugerman, S., Hudes, M., ... McDevitt, K. (2017). Impact of California Children's Power Play! Campaign on Fruit and Vegetable Intake and Physical Activity among Fourth- and Fifth-Grade Students. American Journal of Health Promotion, 31(3), 189-191. https://doi.org/10.4278/ajhp.141125-ARB-592

Krishnan, S., Gambhir, S., Luecke, E., \& Jagannathan, L. (2016). Impact of a workplace intervention on attitudes and practices related to gender equity in Bengaluru, India. Global Public Health, 11(9), 1169-1184.

https://doi.org/10.1080/17441692.2016.11561 40

Kwang, N. B., Mahayudin, T., Yien, H. L., Karim, A. K. A., Teik, C. K., \& Shan, L. P. (2016). Effect of an educational intervention on knowledge of human papillomavirus vaccination among pre-university students in Malaysia. Asian Pacific Journal of Cancer Prevention, 17(1), 267-274. https://doi.org/10.7314/APJCP.2016.17.1.267

McCuskee, S., Garchitorena, A., Miller, A. C., Hall, L., Ouenzar, M. A., Rabeza, V. R., ... Bonds, M. H. (2018). Child malnutrition in Ifanadiana district, Madagascar: associated factors and timing of growth faltering ahead of a health system strengthening intervention. Global Health Action, 11(1). https://doi.org/10.1080/16549716.2018.14523 57

Nitschke, M., Krackowizer, A., Hansen, A. L., Bi, P., \& Tucker, G. R. (2017). Heat health messages: A randomized controlled trial of a preventative messages tool in the older population of south Australia. International Journal of Environmental Research and Public Health, 14(9). https://doi.org/10.3390/ijerph14090992

Power, A. D. (2018). Cyberpsychology and Society Current Perspectives. In Cyberpsychology and Society (1st ed.). https://doi.org/https://doi.org/10.4324/978131 5160962

Rimi, N. A., Sultana, R., Ishtiak-Ahmed, K., Rahman, M. Z., Hasin, M., Islam, M. S., ... Luby, S. P. (2016). Understanding the failure of a behavior change intervention to reduce risk behaviors for avian influenza transmission among backyard poultry raisers in rural Bangladesh: A focused ethnography. BMC Public Health, 16(1), 1-15. https://doi.org/10.1186/s12889-016-3543-6

Sheikh, A., Vadera, S., Ravey, M., Lovatt, G., \& Kelly, G. (2017). A social norms approach to changing school children's perceptions of tobacco usage. 
Health Education, 117(6), 530-539. https://doi.org/10.1108/HE-01-2017-0006

Susilowati, D. (2016). Promosi Kesehatan (1st ed.). Jakarta: Kementerian Kesehatan RI.

Suswani, A., Arsunan, A., Amiruddin, R., Zulkifli, A., \& Ariyanti, S. (2018). Arsunan, AA \& Amiruddin, Ridwan \& Zulkifli, Andi \& Ariyanti, S.. (2018). Knowledge, ARV Access and Compliance of PlhIV before and after Providing Health Education Based on Community ARV and Adherence Support Group (Caasg) in Bulukumba Regency. Indian Jour. Indian Journal of Public Health Research \& Development, 9(7), 145-150. https://doi.org/10.5958/09765506.2018.00629.0

Vallentin-Holbech, L., Rasmussen, B. M., \& Stock, C. (2018). Effects of the social norms intervention The GOOD Life on norm perceptions, binge drinking and alcohol-related harms: A clusterrandomised controlled trial. Preventive Medicine Reports, 12(October), 304-311. https://doi.org/10.1016/j.pmedr.2018.10.019
Vidal Orge, M. P., Regueira Vidal, P. P., Martínez Barrios, J., \& Ucha Fernández, J. (2018). Vaccinating is not just a matter for children: Adult immunization schedule. Vacunas, 19(1), 4-7. https://doi.org/10.1016/j.vacun.2018.03.005

Zanjani, F., Allen, H., Schoenberg, N., Martin, C., \& Clayton, R. (2018). Acceptability of intervention materials to decrease risk for alcohol and medication interactions among older adults. Evaluation and Program Planning, 67, 160-166. https://doi.org/10.1016/j.evalprogplan.2017.12. 010

Zhu, Y., Feng, X., Li, H., Huang, Y., Chen, J., \& Xu, G. (2017). A randomized controlled trial to evaluate the impact of a geo-specific poster compared to a general poster for effecting change in perceived threat and intention to avoid drowning 'hotspots' among children of migrant workers: evidence from Ningbo, China. BMC Public Health, 17(1), 1-9. https://doi.org/10.1186/s12889-017-4462-x 